Article

\title{
Towards a Comprehensive Valuation of Water Management Projects When Data Availability Is Incomplete-The Use of Benefit Transfer Techniques
}

\author{
Michael Ahlheim ${ }^{1, *}$, Oliver Frör ${ }^{2, \dagger}$, Jing Luo ${ }^{3, \dagger}$, Sonna Pelz ${ }^{1, \dagger}$ and Tong Jiang ${ }^{4,5}$ \\ 1 Institute of Economics, University of Hohenheim, Stuttgart 70593, Germany; \\ E-Mail: s.pelz@uni-hohenheim.de \\ 2 Institute for Environmental Sciences, University of Koblenz-Landau, Landau 76829, Germany; \\ E-Mail: froer@uni-landau.de
}

3 Research Center for China's Borderland History and Geography, Chinese Academy of Social Sciences, Beijing 100732, China; E-Mail: ljing25@163.com

4 National Climate Center, China Meteorological Administration, Beijing 100081, China; E-Mail: jiangtong@cma.gov.cn

5 School of Geography and Remote Sensing/Collaborative Innovation Center on Forecast and Evaluation of Meteorological Disasters, Nanjing University of Information Science and Technology, Nanjing 210044, China

$\dagger$ These authors contributed equally to this work.

* Author to whom correspondence should be addressed; E-Mail: ahlheim@uni-hohenheim.de; Tel.: +49-711-4592-3596; Fax: +49-711-4592-4081.

Academic Editor: Markus Disse

Received: 30 March 2015 / Accepted: 13 May 2015 / Published: 22 May 2015

\begin{abstract}
In this paper we deal with the problem of missing data in environmental cost-benefit analysis. If government pursues the goal of maximizing social welfare, this implies that public funds should be allocated to those uses where they generate the highest net social benefit. This criterion makes it necessary to conduct cost-benefit analyses for public projects. While the assessment of project costs is typically rather straightforward, a comprehensive assessment of the project benefits is more complicated because one has to consider that also people living far away from the project site might benefit from that project. Neglecting these so-called passive use benefits would lead to a systematic undervaluation of environmental projects, thereby reducing their chances of being realized.
\end{abstract}


A comprehensive cost-benefit analysis would, therefore, require benefit assessment studies in all areas where passive use values might occur. Obviously, this would be impossible. In this paper we show how the assessment of the social benefits from environmental projects can be enhanced even with an imperfect database by using benefit transfer techniques. This is also illustrated empirically using an example from Northwest China.

Keywords: sustainable water management; contingent valuation method; benefit transfer; passive use values

\section{Introduction}

In this paper we deal with the problem of missing data for benefit assessment in the context of environmental cost-benefit analysis. If government pursues the goal of maximizing the overall welfare of society, which it is expected to do, this implies that scarce public funds should be allocated to those uses where they generate the highest (marginal) net social benefit. In the U.S., these principles were already laid down by Ronald Reagan in his Executive Order 12291: “... (b) Regulatory action shall not be undertaken unless the potential benefits to society for the regulation outweigh the potential costs to society; (c) Regulatory objectives shall be chosen to maximize the net benefits to society; ... (e) Agencies shall set regulatory priorities with the aim of maximizing the aggregate net benefits to society ..." [1]. These guidelines of public decision making were confirmed by Bill Clinton in 1993 in his Presidential Executive Order 12866: "In deciding whether and how to regulate, agencies should assess all costs and benefits of available regulatory alternatives, including the alternative of not regulating. ... Further, in choosing among alternative regulatory approaches, agencies should select those approaches that maximize net benefits ..." [2].

This allocation decision criterion makes it necessary to carry out cost-benefit analyses for all public projects of major importance, especially in an environmental context where the accruing benefits are often not easy to quantify. The assessment of the implementation costs of public projects is typically rather straightforward since they mainly consist of the costs of inputs that are traded in markets, so that they can be valued on the basis of market prices. This also holds true for the calculation of foregone profits, which often play an important role in the context of land use changes for environmental preservation. Things are different when it comes to appraising the social benefits accruing from an environmental project because for many environmental "goods" like biodiversity, clean air, or a beautiful landscape, no market prices are available. Therefore, for their assessment, special techniques like, e.g., the Contingent Valuation Method (CVM) or Attribute-Based Choice Methods like Choice Experiments must be employed [3-6].

Another complication of environmental valuation arises from the fact that, in many cases, the beneficiaries of an environmental project, for instance a reforestation project, are not located in one single place only (like the project site) but are distributed over many different places. The reason for this phenomenon is that environmental improvements often also have a symbolic importance, which is perceived and appreciated also by people living far away from the project site. This importance is independent of a direct utilization of the environmental goods in question. The protection of e.g., 
the rain forests in a country, may also be appreciated by people who never visit such a forest. Though they have never been there and do not intend to go there in the future personally, they experience an increase in utility when they read in the papers that measures have been taken to protect some forest areas against economic exploitation or that they have been reforested. Other people might feel happy when they learn that water quality in a formerly polluted river has been improved such that people now can go fishing and swimming in that river in spite of the fact that they personally will never go there. Adamowicz et al. [6] refer to this kind of value as passive use value: "Passive use value is the economic value arising from a change in environmental quality (or any other situational change) that is not reflected in any observable behavior. That is, changes in recreational demand, purchasing behavior, or other observable action do not necessarily take place." It is clear that passive use values accrue not only to people on site but, at least potentially, to people living all over a country, and, in the case of rain forests or the preservation of certain keystone species even all over the world [7]. For a cost-benefit comparison as an allocation decision criterion the Total Economic Value (TEV) of an environmental improvement has to be compared to the costs of the project that caused that improvement. The TEV comprises (active) use values, which are connected with observable utilization activities on the one hand and passive use values on the other (cf., e.g., [6]). Neglecting passive use values, therefore, leads to a systematic undervaluation of environmental improvements, thereby reducing the chances of the respective environmental projects being realized if their implementation depends on a cost-benefit comparison.

A comprehensive cost-benefit analysis of an environmental project would therefore require conducting nationwide (in some cases even global) benefit assessment studies while the costs of the project could be measured locally, i.e., on the project site. Obviously, such a comprehensive benefit assessment would be difficult if not impossible under organizational as well as financial aspects. Under real-world conditions, cost-benefit practitioners must do with incomplete data sets collected locally at some pilot sites and then try to infer the total benefits of environmental projects from this imperfect database. One possibility to deal with this problem of missing data is the application of so-called benefit transfer techniques in combination with Contingent Valuation Method (CVM) studies. Benefit transfer requires conducting a primary CVM study in a more or less characteristic study site. Then other regions are identified which are not too different under socio-economic aspects from the study site and where people are also expected to receive benefits from the environmental project in question. In a next step, the CVM-results from the study site are extrapolated to these additional sites via value transfer or value function transfer as described below. This procedure allows approximation of at least roughly also the benefits accruing to people not living in the study site, though no additional CVM study is conducted with them. Since it can be expected that people living in the region where an environmental project (like a reforestation project) is implemented will obtain active use values as well as passive use values (like e.g., existence values or bequest values etc.) and since these values cannot be separated properly in a CVM study, two different CVM surveys will have to be conducted for a comprehensive assessment of the overall benefits accruing from such an environmental project. One CVM study must be conducted at the project site itself to assess the active and passive use benefits accruing to the people living there. For the ensuing benefit transfer study then a primary CVM survey must be conducted at a so-called "study site" which is characteristic of sites where people perceive only the passive use values of the environmental project in question. Then the results of this study can 
be extrapolated via benefit transfer as explained below to all other sites where passive use values are expected but not assessed explicitly through additional CVM surveys. Since this paper focuses on the problem of dealing with missing data in benefit appraisal studies, we will neglect the cost assessment aspects of environmental cost-benefit analysis here.

The working of the benefit transfer technique is also demonstrated empirically in this paper using an example where the social benefits accruing from a water management project in the Tarim Basin in Xinjiang Autonomous Region in Northwest China are assessed not only in the project area but also in five megacities of China where, in only one of these cities (Beijing), a CVM survey has been conducted. Based on this example we discuss the advantages and disadvantages of the benefit transfer method as a tool for the assessment of the total value of water projects which generate a high degree of passive use values accruing in various different places which are widely scattered geographically, so that it is not feasible to conduct separate valuation studies in each of these sites in order to assess the total value of the water project comprehensively.

The paper is structured as follows. Section 2 reviews the two environmental valuation techniques used in the present study-contingent valuation and benefit transfer. Section 3 of this paper introduces the environmental site in question and the water management project to be valued. Section 4 reports results. This opens with a consideration of the data gathered through a contingent valuation survey in Beijing in 2013. The section continues with an exemplary application of benefit transfer and ends with a rough approximation of the megacity-wide social value of a more sustainable water management in the Tarim Basin.

\section{Methods}

\subsection{The Contingent Valuation Method}

Welfare economic theory postulates that an increase in society's welfare is a function of the utility changes of all members making up a society. Individual utility changes, in turn, can be measured in monetary terms by the Hicksian Compensating Variation which can be interpreted as an individual's willingness to pay (WTP) to obtain a desired good or willingness to accept (WTA) compensation to forego enjoying the good [8]. Applying this concept to the environmental context leads to the well-established practice of assessing individuals' WTP for the realization of a particular environmental project in a first step and extrapolating individual WTP values in a second step to obtain the social value of this project. This would be done ideally by summing up the WTP of all households affected by the environmental project in question [9]. In practice, of course, it is not possible to elicit the individual WTP of all households concerned. Instead, the average WTP of a representative sample of the affected population is assessed and then multiplied by the number of all households. If an environmental change leads to decreases in the utility of people (e.g., after the occurrence of environmental damages) the Hicksian Compensating Variation equals the minimum amount of money they would have to be given in order to be compensated in utility terms for that loss. This amount is usually termed their willingness to accept compensation (WTA).

The WTP for environmental goods, which are typically not bought and sold in markets, is empirically not observable. Due to the absence of market prices and demand functions researchers 
have to rely on specific methods to obtain WTP values. The present study makes use of the Contingent Valuation Method (cf., [10,11]). Contingent valuation is a survey-based technique; it simulates a hypothetical market for a particular environmental good and assesses the value of this good by directly asking respondents to state their WTP for its provision. An analogous procedure for the elicitation of people's WTA by directly asking them would be problematic because of the obvious incentive for respondents to exaggerate the money amounts they claim for compensation. For this reason, literature generally advises against using WTA measures in environmental valuation studies [12]. Ideally, the sample of a CVM survey is representative of all households affected by the environmental project in question. If this is the case, the sample's average WTP reflects the average WTP of all those who would benefit from the environmental project. Hence, multiplication of the sample's average WTP by the number of all beneficiaries yields the social value of the considered project.

CVM surveys are a suitable way for assessing the total economic value (TEV) of environmental projects. As mentioned above, the TEV is commonly decomposed into so-called use values and passive use values (s. [6] or [3]), which are sometimes also called nonuse values (cf., [13]). Use values refer to the benefits accruing to the users of an environmental good (e.g., spending time at a waterside). Passive use values encompass all kinds of benefits which people can enjoy without actively utilizing an environmental good ( $c f$. , [6]). Revealed preference techniques, like the travel cost method or hedonic pricing, exclusively focus on the users of environmental goods (the visitors of parks, the owners of houses located at immediate distance of a natural resource, etc.) and are unsuitable for the assessment of passive use values [9]. Therefore, valuation methods that assess people's WTP directly, like the CVM, are preferable over revealed preference methods whenever an environmental good generates substantial passive use values [3].

Water management projects of national importance may have, in addition to their positive effects on local people's livelihood, considerable passive use values. This argument also holds true for the water management project considered in our empirical example below ( $c f$., Section 3.2). One peculiarity of passive use values is that not only those living in immediate proximity to the project site would benefit from the accruing environmental improvements, but also people living far away may experience an increase in their wellbeing. Since it is expected that people all over China might at least psychologically benefit from a more sustainable water management in the Tarim Basin as considered in our example below, a comprehensive CVM survey should assess the preferences of all people living in China. Since such a direct benefit assessment covering the whole of China is not feasible, a less ambitious but realistic strategy consists of conducting a CVM survey in a "typical" study site, e.g., in one of China's megacities, and then extrapolating the WTP results gained there to all other Chinese megacities by means of the benefit transfer methodology. This strategy is illustrated in our empirical example in Sections 3 and 4 below.

\subsection{Benefit Transfer}

The term "benefit transfer" describes the extrapolation of the benefits accruing from some environmental project assessed at one or several "study sites" to some other target site or "policy site" where no primary benefit assessment study has been conducted [14]. In the context of the present study, this means that we transfer the passive use value of the Tarim water management project 
assessed in Beijing (the "study site") to other Chinese megacities (the "policy sites"). Benefit transfer is frequently used in practice. This holds especially true for the U.S., where agencies rarely conduct original environmental valuation studies but mostly rely on benefit transfer [15]. In this section, different variants of benefit transfer shall be introduced and the criticism towards the methodology will be briefly addressed. Comprehensive overviews on the benefit transfer methodology have been provided elsewhere ( $c f$., e.g., [16,17], Chapter 17).

There are different kinds of benefit transfer variants discussed in the literature, namely value transfer and benefit function transfer ( $c f .$, [18]). Value transfer is the simplest variant; it consists of transferring a WTP point estimate for a particular environmental good identified in the literature to a policy site for which the value of the same (or a similar) environmental good is needed. Hence, value transfer relies on the assumption that the population at the policy site P has the same average WTP as the population at the study site S. Put formally,

$$
W T P_{S}=W T P_{P}
$$

As can be inferred from its name, the second variant of benefit transfer involves the transfer of the value function or WTP function estimated econometrically at the study site to the policy site. For example, in a simple and practical form, WTP might be perceived as a linear function of socio-economic (e.g., income) and demographic characteristics of the population (e.g., age) at the study site, i.e.,

$$
W T P=\beta_{0}+\beta_{1}(\text { income })+\beta_{2}(\text { age })
$$

Assuming that the environmental good is provided in equal quantity and quality at both sites, Equation (2) allows the analyst to tailor the WTP per household at the policy site. This is done by substituting site-specific values for income and age into the WTP function, while maintaining the regression coefficients, $\beta_{1}$ and $\beta_{2}$, and the constant term $\beta_{0}$ assessed at the study site. Classical as well as Bayesian statistical approaches can be used to combine data from the study site and from the policy site $(c f$. ., [19]). There is little agreement among researchers about which variant of benefit transfer-Simple value transfer or function transfer-Provides the most accurate results. [14] show that simple value transfers yield more accurate results than function transfers when the policy site context resembles the study site context in terms of its population and the characteristics of the environmental good. However, function transfer is preferable when the study site and the policy site are dissimilar. Likewise, there is no consensus about whether classical statistical methods or Bayesian approaches are more appropriate when transferring a value function from one site to another [19].

When it comes to function transfer, analysts have two possibilities at hand for obtaining a value function for a particular environmental good: adopting a function which has been reported in a single study or estimating a regression equation based on the results of multiple environmental valuation studies assembled by meta-analysis. Meta-analysis typically encompasses the following steps (cf., [18]): first, researchers collect all available environmental valuation studies on the environmental good in question (e.g., a particular ecosystem, national parks, etc.); second, they create a dataset by coding these studies with respect to WTP per unit, attributes of the study site like the quantity of the environmental good available or the availability of substitute goods (e.g., proximity to other similar ecosystems or national parks), the methodological details of the studies (e.g., stated or revealed 
preference methods, survey mode, sampling approach, etc.) and the population statistics (e.g., income levels, age, gender, etc.) reported in the primary studies. Based on such a data set, the WTP per unit can be analysed as a function of the set of available variables by means of regression analysis. Doing so, the analyst obtains a meta-analysis equation that provides the basis of the benefit transfer exercise.

It is beyond all question that meta-analysis is more time-intensive and, hence, more costly than the simple variant of benefit function transfer. Given this drawback, the question arises whether ([18], p. 83) and other proponents of meta-regression analysis are right when claiming that this approach is "one of the biggest advances in benefit transfer".

Boyle et al. [15] conclude that there is substantial evidence that pooled data approaches are superior to simple function transfer. This is because meta-analysis-based benefit transfer overcomes one of the biggest drawbacks of the standard function transfer; it relaxes the assumption that the statistical relationship between WTP and the explanatory variables is the same between the policy site and a single study site (ibid.). However, meta-analysis-based benefit transfer requires a sufficiently large number of primary studies on similar environmental goods with well-reported and statistically robust results as well as a researcher's ability to identify these studies. The frequently praised Environmental Values Reference Inventory (EVRI), which is a database where the results of multiple environmental valuation studies have been assembled with the overall objective of facilitating benefit transfer, for example, is only open for citizens of member countries. Since neither Germany nor China belongs to the group of member countries, the EVRI database was not much help in the context of the present study. Furthermore, estimating WTP functions based on pooled data is also prone to a lot of errors. In many practical applications, researchers assembled environmental valuation studies which employed different, and in many cases, incompatible valuation approaches. For example, WTP functions are regularly estimated based on the results of studies that employed travel cost models (TCM) on the one hand and studies that made use of contingent valuation studies on the other. This means that valuation techniques assessing only use values (TCM) and techniques assessing use and passive use values (CVM) were mixed together. It is also common practice to include WTP and willingness to accept compensation (WTA) simultaneously as welfare measures into the same dataset from which the value function is then be estimated.

In view of enhancing the soundness of the methodology, some guidelines for conducting benefit transfer have been formulated. The proponents of benefit transfer still cite the three "ideal criteria" proposed by [20] in Water Resources Research and suggest following these criteria as closely as possible. These criteria require that (1) the environmental good valued at the study site and the policy site are identical; (2) that the populations affected by changes in the quality or quantity of the environmental good have the same characteristics in both sites; and (3) that the assignment of property rights at both sites implies the same welfare measure, i.e., WTP or WTA. However, even if these guidelines are strictly followed by all practitioners, the validity of environmental values assessed with the benefit transfer method can still be questioned. Maybe the greatest shortcoming of benefit transfer is that individual preferences of those living at the policy site are completely neglected [21]. It is assumed that the members of the target population have the same preferences as the participants of the primary study. This assumption is, of course, highly questionable, even in the ideal case that both populations resemble each other in terms of their demographic and cultural characteristics. 
One decade ago, renowned environmental valuation researchers such as [11], highlighted that benefit transfer "cannot, at the moment, be relied upon to produce valuation estimates which are statistically indistinguishable from 'true' values". With the development of meta-analysis and benefit transfer databases such as EVRI, the field of benefit transfer has, certainly, advanced. In spite of this, most researchers still conclude that benefit transfer "will never take the place of a carefully conducted primary study" [15]. Nevertheless, in cases where the benefits from a public project accrue in many different places which are geographically widely scattered so that it is not possible to assess all these benefits by separate CVM studies, it seems to be better to approximate the overall benefits by using benefit transfer than to ignore all benefits accruing in other places than the study site. This will be demonstrated in the following sections at the example of a water management project in the Tarim Basin.

\section{Water Management in the Tarim Basin}

\subsection{Water Shortage in the Tarim Basin}

The Tarim River, Central Asia's longest inland river, is located in a desert region in Northwest China. This river gives the Tarim Basin its name, which covers the southern part of Xinjiang Uyghur Autonomous Region. The inhabitants of the Tarim Basin largely depend on the supply of water by the Tarim River and its tributaries. Any kind of agricultural and industrial activity in this extremely dry region depends on surface and groundwater [22]. The extension of agricultural and industrial production, accompanied by an impressive population growth, has contributed to the economic development of the region. However, the natural environment has been deteriorating due to unsustainable water management. The extensive water use in the upper reaches of the Tarim River prevents a permanent water supply at the lower reaches. As a consequence, the unique dryland ecosystems of the Tarim Basin are threatened [23]. Due to the deterioration of the riparian poplar forests and grasslands, the inhabitants of the Tarim Basin are increasingly exposed to sandstorms, dust, and rising temperatures. Furthermore, there is a loss in biodiversity and the progressing desertification renders the formerly beautiful landscape into a lifeless desert. In view of the warnings of several climate experts (cf., e.g., [24]), a more sustainable water management is urgently needed. The local impact of global warming may cause a complete desiccation of the Tarim River. Under this scenario the southern part of Xinjiang would become uninhabitable and many rare plant and animal species would become extinct.

The Chinese Government has already undertaken considerable effort to restore the natural ecosystems at the lower reaches of the Tarim River. [25] estimates that public investment into water allocation projects amounts to 11 billion Chinese RMB (approximately 1.5 billion EUR). However, even though there is increasing awareness of the water-related environmental issues among scientists and policy makers, the integration of natural ecosystems into water management policy remains difficult. One reason why policy makers still tend to neglect environmental parameters is the lack of information about the value of a more sustainable water management in the Tarim Basin for Chinese society. Until now, little research has been conducted on the effect of a more sustainable water management in the Tarim Basin on society's wellbeing. The existing studies are hardly helpful for determining the overall benefit of this project. Krutilla [26], for example, used market-price based 
techniques to estimate unit values of different ecosystems in the lower reaches of the Tarim. However, these values do not reflect the multiple passive use values of the natural ecosystems. Loomis et al. [27] estimated the value of China's forest ecosystem services. Similar to the previously cited study, this assessment may underestimate the actual value of forest, because market-price-based methods dominated this assessment. Interestingly, however, the value of Xinjiang's forest ecosystem services was the lowest in the whole of China in this study. Loomis et al. [28] conducted a CVM survey to assess the social value of poplar forests in the Tarim Basin. The authors assessed only the preferences of Han Chinese farmers working in the State Farms along the Tarim River. Hence, the WTP estimate does neither reflect the benefits accruing to the permanent residents of the Tarim Basin nor to people living in other parts of the country.

In the study included here, we demonstrate the possibilities to reach a more comprehensive valuation of a sustainable water management scheme in the Tarim basin by also taking into account the passive use values created by this project for people living far away from the project site (the exact description of the project scenario can be found in Table A1). As a demonstration, we first assess the passive use benefits accruing to people living in Beijing as an example of a Chinese megacity (our "study site") and then extrapolate these results to the citizens of Shanghai (our "policy site") to show how benefit transfer works in practice. In the next step, we generalize our results using benefit transfer to China's "big five" megacities, i.e., Beijing, Shanghai, Shenzhen, Guangzhou and Tianjin.

\subsection{Social Benefits of an Improved Water Management Scheme}

In the present study the following value components of a more sustainable water management regime in the Tarim Basin can be identified. Due to its positive impact on the natural vegetation along the Tarim River, the water management project in question is expected to have considerable use value for the local populations. For example, the riparian forests along the Tarim River protect the Basin's oasis cities from sandstorm and dust. Hence, if these ecosystems are restored, the local households and firms would be less exposed to these two kinds of environmental hazards. Since a more sustainable water management scheme is particularly urgent in view of the wellbeing of future generations, the project has important bequest values. In view of an increasing number of Chinese households which have the chance and budget to travel, many people may wish to preserve the possibility to visit the Tarim Basin one day in the future; hence, this so-called option value further adds to the passive use values of the water management project. As first theorized by [29], people may gain satisfaction from the pure knowledge about the existence of an environmental good. In line with this supposition, it is expected that the natural ecosystems of the Tarim Basin also have a considerable existence value.

Except for the project's direct use value, which could only be enjoyed by the inhabitants of the Tarim Basin, all other value components are likely to contribute also to the wellbeing of people living in other parts of China. Therefore, not accounting for its passive use values would lead to a dramatic underestimation of the water management project's overall social benefit. However, conducting an environmental valuation study that is representative of all Chinese people is organizationally and financially unfeasible. Therefore, we conducted two CVM surveys at two exemplary sites. We explored the preferences of local people during workshops in different cities in Xinjiang. Then, we interviewed approximately 2500 residents in Beijing. The present study focusses on the Beijing survey and the 
extrapolation of its results to other megacities in China; the results of our Xinjiang survey have been reported elsewhere $[30,31]$ ) and are not part of this analysis due to our focus on the passive use values of the Tarim water management scheme.

\subsection{A CVM Survey in Beijing}

We gathered our data through personal interviews that were based on a standardized questionnaire (cf., Table 1). We opted for this comparatively time- and cost-intensive interview mode because of the complexity of the survey topic and in order to minimize selection bias. In Beijing, many people, especially the elderly and the poor, are not acquainted with the internet and, as it turned out during the survey preparation phase, some of them are not even able to read. Hence, personal interviews appeared to be the best option for gathering a representative sample and maximizing data quality. During these interviews we informed the respondents about the current situation in the Tarim Basin, thereby focusing on water shortage and its environmental impacts. Then we introduced the "Tarim Environmental Preservation Plan", a hypothetical water management project that would lead to restoration and conservation of the natural ecosystems along the Tarim River (cf., Table 2). Subsequently, we informed the respondents that the new water management project could not be financed out of existing funds alone. Therefore, the central government would have to increase taxes, implying a higher cost of living for households all over China. We assessed respondents' WTP using the dichotomous choice elicitation question format ( $c f$., [32]) with bids from 10 to 200 RMB. Respondents were told that the government would implement the "Tarim Environmental Preservation Plan" only if the majority of survey participants voted in favor of the project. The exact wording of the payment scenario and the referendum question is displayed in the appendix. Using a quota-based intercept survey mode, we obtained a sample of 2438 observations. Respondents' characteristics closely reflect the socio-economic and demographic characteristics of the general population of urban Beijing (Table 3 summarizes the sample characteristics).

Table 1. Description of the contingent valuation method (CVM) questionnaire.

\begin{tabular}{|c|c|}
\hline Part & Description \\
\hline (A) Warm up questions & $\begin{array}{l}\text { Previous knowledge about the Tarim River and environmental problems } \\
\text { affecting people's livelihood in the Tarim Basin }\end{array}$ \\
\hline (B) Description of the status quo & $\begin{array}{l}\text { Description of the key environmental features of the Tarim River and the } \\
\text { riparian ecosystems; the environmental problems caused by the extensive use } \\
\text { of water resources in the past; and some related questions }\end{array}$ \\
\hline $\begin{array}{l}\text { (C) Description of the water } \\
\text { management project }\end{array}$ & $\begin{array}{l}\text { Depiction of the "Tarim Environmental Preservation Plan" (cf., Table } 2 \text { and } \\
\text { the project scenario in Table A1) }\end{array}$ \\
\hline (D) Value assessment & $\begin{array}{l}\text { Payment scenario, followed by a dichotomous choice question to assess } \\
\text { respondents' WTP for a more sustainable water management project in the } \\
\text { Tarim Basin }(c f ., \text { Table A1) }\end{array}$ \\
\hline (E) Follow-up questions & $\begin{array}{l}\text { Collection of relevant information regarding respondents' } \\
\text { - } \quad \text { motivation to support or reject the water management project } \\
\text { - } \quad \text { socio-economic characteristics } \\
\text { - } \quad \text { attitudes towards several aspects of life and respondents' personality }\end{array}$ \\
\hline
\end{tabular}


Table 2. Description of the environmental change resulting from a more sustainable water management.

\begin{tabular}{|c|c|}
\hline Scenario & Description \\
\hline Status quo situation & $\begin{array}{l}\text { Extensive water use in the upper and middle reaches of the Tarim River has } \\
\text { led to a destruction of the natural environment. This development has, } \\
\text { among other things, the following consequences: } \\
\text { - } \text { more sandstorms } \\
\text { - } \quad \text { more dust days } \\
\text { - } \quad \text { extinction of native plant and animal species } \\
\text { - } \quad \text { progressive desertification of the landscape }\end{array}$ \\
\hline $\begin{array}{l}\text { Situation subsequent to an } \\
\text { improved water } \\
\text { management scheme }\end{array}$ & $\begin{array}{l}\text { Expected impacts of a science-based water management: } \\
\text { - } \quad \text { secured water supply in the lower reaches } \\
\text { - } \quad \text { restoration of riparian forests and grasslands } \\
\text { - } \quad \text { less sandstorms and dust } \\
\text { - } \quad \text { survival of native animals and plants } \\
\text { - } \quad \text { prevention of desertification and hence conservation of the area for } \\
\text { future generations }\end{array}$ \\
\hline
\end{tabular}

Table 3. Characteristics of the population at the study and policy site.

\begin{tabular}{cccc}
\hline Site Characteristics & $\begin{array}{c}\text { Beijing } \\
\text { (Study Site) }\end{array}$ & $\begin{array}{c}\text { Shanghai } \\
\text { (Policy Site) }\end{array}$ & Difference between Sites \\
\hline Number of households & 4.006 Mio. & 6.969 Mio. & -2.963 \\
$\quad$ Consumer Price Index ${ }^{1}$ & 105.6 & 105.2 & 0.4 \\
Mean distance from Tarim Basin & & & -786 \\
$-\quad$ Linear distance $(\mathrm{km})$ & 3039 & 3825 & $0 \mathrm{~h} 35$ \\
$-\quad$ Flight (hours) & $6 \mathrm{~h} 50$ & $6 \mathrm{~h} 15$ & \\
\hline
\end{tabular}

\begin{tabular}{|c|c|c|c|}
\hline & Beijing $(N=\mathbf{2 4 3 8})$ & Shanghai $(N=791)$ & Difference between Samples \\
\hline Respondent Characteristics & Mean (std. dev.) & Mean (std. dev.) & $\begin{array}{c}p \text {-value from } t \text {-test of Equal Means } \\
\text { in the Study and Policy Site }\end{array}$ \\
\hline $\begin{array}{l}\text { Monthly disposable household } \\
\text { income (in } 1000 \mathrm{RMB} \text { ) }\end{array}$ & $\begin{array}{c}8.485 \\
(7.749)\end{array}$ & $\begin{array}{l}10.512 \\
(7.594)\end{array}$ & 0.000 \\
\hline Male & $\begin{array}{c}0.504 \\
(0.506)\end{array}$ & $\begin{array}{c}0.529 \\
(0.499)\end{array}$ & 0.023 \\
\hline Age & $\begin{array}{c}40.02 \\
(15.408)\end{array}$ & $\begin{array}{l}40.08 \\
(17.0)\end{array}$ & 0.534 \\
\hline Education $^{2}$ & $\begin{array}{c}4.318 \\
(1.318)\end{array}$ & $\begin{array}{c}4.306 \\
(1.209) \\
\end{array}$ & 0.666 \\
\hline Household size & $\begin{array}{c}2.872 \\
(2.872)\end{array}$ & $\begin{array}{c}3.095 \\
(1.145)\end{array}$ & 0.000 \\
\hline
\end{tabular}

Notes: ${ }^{1}$ Figures published in the Statistical Yearbooks 2012 of Beijing and Shanghai [34,38]; ${ }^{2}$ A respondent's highest education level was assessed by means of seven categories. 4 means "senior high" and 5 "college graduate". 


\section{Results and Analysis}

\subsection{Primary Study: Beijing Residents' WTP for a Sustainable Water Management Project in Northwest China}

To assess the sample's average WTP we estimate a simple univariate probit model, thereby regressing the binary variable, derived from a respondent's answer to the referendum question ("yes" or "no"), on the bid variable. The software package STATA13 provides the following output (in rounded figures):

$$
\operatorname{Prob}(\text { yes })=\beta_{0}+\beta_{1}(\text { bid })=0.642-0.006(\text { bid })
$$

Given the negative sign of the parameter estimate, the likelihood of agreement, i.e., that a respondent's answer to the referendum question is "yes", decreases as the bid level increases. This result is, of course, what economic theory suggests and confirms the plausibility of the collected data. The estimated regression coefficient $\widehat{\beta}_{1}$ and the constant term $\widehat{\beta}_{0}$ build the basis for calculating the sample's average WTP. As shown by [33], average WTP equals the negative ratio of the constant term and the parameter estimate, i.e.,

$$
W T P=-\frac{\beta_{0}}{\beta_{1}}=107
$$

Thus, in urban Beijing, households are, on average, willing to contribute approximately $1.3 \%$ of their disposable monthly income to the water management project in the Tarim Basin. According to the population census, there are 4.006 million households in urban Beijing at the time of the survey [34]. Hence, the social benefits accruing to Beijing residents per month from the "Tarim Environmental Preservation Plan" amount to 428.642 million RMB. Naturally, this figure has only limited practical relevance. This monthly WTP of all Beijing residents would have to be extrapolated in terms of the project duration, discounted and adjusted for inflation in order to attain the net present value this project has for all Beijing residents taken together.

To learn about the main determinants of WTP as well as the plausibility of this estimate, respondents' answers to the referendum questions have been explored by means of regression analysis. The results of two probit models are summarized in Table 4. Table A1 in the appendix offers a detailed variable description. In model 1, merely the bid and the income variable are included as control variables. Like in the model without control variables ( $c f$., Equation (3)), the magnitude of the bid negatively affects the likelihood of agreeing with the referendum question. Furthermore, as income increases, the probability of answering "yes" to the elicitation question also increases. In other words, respondents with higher incomes have a higher WTP, which is, of course, plausible. The marginal effect of the income variable $(\mathrm{d} y / \mathrm{d} x)$ indicates that a 1000 RMB increase in a respondent's income would increase the likelihood of agreeing with the referendum question by $0.4 \%$. Hence, there is an observable, but moderate, income effect. 
Table 4. Probit regression models displaying determinants of supporting the water management program.

\begin{tabular}{ccccccccc}
\hline \multirow{2}{*}{ Dependent Variable: WTP } & \multicolumn{3}{c}{ Model 1 } & & \multicolumn{3}{c}{ Model 2 } \\
\cline { 2 - 3 } \cline { 6 - 8 } & Coef. & s.e. & $\mathbf{d} \boldsymbol{y} / \mathbf{d} \boldsymbol{x}$ & & Coef. & s.e. & $\mathbf{d} \boldsymbol{y} / \mathbf{d} \boldsymbol{x}$ \\
\hline CONSTANT & $0.559^{* * *}$ & 0.053 & & & 0.238 & 0.093 & \\
BID & $-0.006^{* * *}$ & 0.000 & -0.002 & & $-0.006 * * *$ & 0.000 & -0.002 \\
INCOME & $0.010^{* * *}$ & 0.004 & 0.004 & & $0.006 *$ & 0.004 & 0.002 \\
MALE & & & & $0.128^{* *}$ & 0.053 & 0.046 \\
EDUCATION & & & & & $0.038^{*}$ & 0.020 & 0.013 \\
HH_SIZE & & & & $0.043 * *$ & 0.020 & 0.016 \\
Observations & 2400 & & & & 2400 & & \\
Log likelihood & -1531 & & & & -1525 & & \\
Pseudo $R^{2}$ & 0.075 & & & 0.079 & & \\
\hline
\end{tabular}

Notes: *** means significant at $1 \%$-level; ** $5 \%$ level; * $10 \%$ level.

In model 2, several demographic variables are added as controls. Based on this extended model conclusions regarding the distribution of the benefits of a more sustainable water management in the Tarim Basin can be drawn. Gender, education and the number of people living in a respondent's household all have a significant effect on WTP. Men have a higher WTP than women; as the education level increases so increases WTP; and respondents with larger households have a higher WTP than others, ceteris paribus. The positive relationship between education and WTP has been reported in other environmental valuation studies, including some CVM surveys in China [35]. Hence, we conclude that a more sustainable water management in the Tarim Basin would be particularly beneficial for people with a relatively high education level. Literature provides mixed results regarding the effects of gender and household size on WTP. A positive relationship between the latter variable and WTP is plausible, because the number of those who would enjoy the environmental improvement to be valued is greater in larger households than in smaller households. However, many CVM studies did not discover such an effect or even reported negative effects [36], which might be due to the fact that budgets are tighter in households with many children. We explain the fact that men have higher WTP than women in our sample by the everyday observation that Chinese men tend to be more generous than Chinese women. In many Chinese families, women manage the household budget and seem to be tighter in spending it than their husbands. Taken together, the results of the regression analysis are plausible and robust, which is an indicator of the validity of the CVM data collected in Beijing.

\subsection{Secondary Study: Using Benefit Transfer to Assess Shanghai Residents' WTP}

As explained above, policy makers could use the WTP value measured in Beijing to approximate the benefits of the Tarim water management project accruing to people in other parts of the country. The present study is particularly suitable for an application of the benefit transfer methodology. This is because the environmental good which has been valued in Beijing is identical to the environmental good to be valued in other Chinese megacities-we wish to assess the benefits from one and the same water management project and we expect that the benefits accruing from this project, which are mainly passive use values, are perceived similarly in all Chinese megacities. Furthermore, the population characteristics of at least some Chinese megacities resemble each other. For example, the residents of 
Shanghai and Beijing have approximately the same average education level and age structure (cf., Table 3). Furthermore, when it comes to the benefit assessment of utility increasing public projects, the appropriate welfare measure is always a WTP measure, in other words, property rights in the context of this water management project are the same for all Chinese megacities. Hence, the three "ideal criteria" for benefit transfer according to [20] are broadly fulfilled in the present study.

However, as soon as we wish to apply a more sophisticated form of benefit transfer, we require comprehensive population statistics for all megacities of interest. In China such data is, however, difficult to access. This holds especially true for non-Chinese researchers. Even though the statistical yearbooks of most Chinese cities are nowadays available in English, the published data is in many cases not precise enough to serve as an input for a benefit transfer application. For example, in the Beijing Statistical Yearbook a reader finds statistics about people's education levels in the municipality of Beijing, which encompasses also economically underdeveloped rural areas, but no separate figures regarding the education level of the urban population.

In view of this lack of official data, we selected the city of Shanghai as an exemplary policy site. Since the authors conducted a representative CVM survey also in Shanghai in 2013 (for a different environmental project) we collected also comprehensive population data for Shanghai in this context (cf., [37]). A particular advantage is that the CVM questionnaire used in Shanghai closely resembles the one used in Beijing. Household characteristics such as income and household size were assessed by means of identical questions and answer scales. Table 3 summarizes the characteristics of the policy site (Shanghai) and compares them to the characteristics of the study site (Beijing) of our present benefit transfer analysis here.

The data provides information on the characteristics of 791 residents living in Shanghai's 12 districts and counties. This area counted 6.969 million households at the time of the data collection [38]. Beijing and Shanghai differ in terms of the monthly disposable household income of an average household, gender ratio and household size. These differences are obvious when comparing the data of our two surveys displayed in Table 3; the official figures also reflect these dissimilarities. Households in Shanghai have, on average, higher incomes, more members and there are relatively more men living in Shanghai than in Beijing. Since all of these three characteristics have a statistically significant effect on WTP ( $c f$., Table 4), these differences should be taken into account when transferring the WTP value assessed in Beijing to Shanghai. In addition to demographic differences, it is to be noted that the linear distance to the Tarim Basin is longer from Shanghai than from Beijing. However, flight time, for example from Shanghai or Beijing to the city of Aksu, an oasis city located at the upper reaches of the Tarim River, is approximately the same ( $c f$., Table 3). Anyway, while it is plausible that the geographical distance from the project site and therewith the time needed to get there has an effect on the use value of a project it should not influence its passive use value.

To assess the benefit of the Tarim water management project accruing to Shanghai citizens we have two possibilities at choice: transferring the point estimate of WTP assessed in Beijing to Shanghai; or transferring the value function or WTP function estimated for the Beijing sample to Shanghai, thereby replacing the mean values measured at the study site by the mean values of the Shanghai sample. The more sophisticated variant of function transfer, which is the meta-regression approach, is not suitable in the case of the present study, because hardly any similar environmental valuation studies have been conducted so far. 
The results of the value transfer exercise and the function transfers are displayed in Table 5. If we simply transfer the point estimate of 107 RMB per household and month, we obtain a social value of approximately 746 million RMB for Shanghai. This figure is much higher than the one that we have computed for Beijing, which is due to the greater number of households living in urban Shanghai. The mean WTP estimate for Shanghai becomes slightly higher if we apply a value function transfer. Table 5 shows the outcome of two kinds of function transfer. Bishop et al. [14] recommended employing only "theory-driven" value functions in benefit transfer exercises. This means that the econometric model underlying a value function transfer should only encompass variables which economic theory postulates to be related to WTP. Such economic variables are, for example, the distance to the site where a particular environmental improvement takes place, the magnitude of the environmental improvement and an individual's income. Since the present study focuses on the same water management project for both sites and because all respondents live at a similar distance from the improvement site (and this distance does not matter anyway for passive use values), we can confine the arguments of the value function to the latter variable in such a theory-driven function, i.e., on income. Hence, we first estimated a model which encompasses merely the bid level and a respondent's income as control variables ( $c f$., model 1 in Table 4). Second, we used the more fully specified model, which includes the bid, income, gender and education as control variables ( $c f$. , model 2 in Table 4) to tailor a value function for Shanghai. Bishop et al. [14] advise against using models with "ad-hoc variables", i.e., with any demographic variable in addition to income. This is because the relationship between several demographic variables and WTP is not consistent across studies. For instance, unlike in the Beijing CVM survey, we observed neither an effect of education nor of gender when determining the key determinants of Shanghai residents' WTP for the protection of rare species in Southwest China (cf., [37]). Hence, if we transfer a value function from one site to another, this goes along with the strong assumption that all statistical effects discovered in the primary site would also be replicated in the policy site-this assumption is reasonable for the income effect, which most CVM studies report, but less realistic for any other respondent characteristic.

Table 5. Willingness to pay in RMB of Beijing and Shanghai residents (benefit transfer).

\begin{tabular}{|c|c|c|c|c|}
\hline \multirow[b]{2}{*}{ Transfer Mode } & \multicolumn{2}{|c|}{ Beijing (Study Site) } & \multicolumn{2}{|c|}{ Shanghai (Policy Site) } \\
\hline & $\begin{array}{l}\text { Mean WTP } \\
(95 \% \text { c.i. })^{1}\end{array}$ & $\begin{array}{l}\text { Social } \\
\text { Value }\end{array}$ & $\begin{array}{c}\text { Mean WTP } \\
(95 \% \text { c.i. })\end{array}$ & $\begin{array}{l}\text { Social } \\
\text { Value }\end{array}$ \\
\hline Value transfer & $107(98 ; 116)$ & 431 Mio. & $107(98 ; 116)$ & 746 Mio. \\
\hline $\begin{array}{c}\text { Function transfer } \\
\text { (theory-driven model) }\end{array}$ & $107(98 ; 116)$ & 429 Mio. & $111(101 ; 120)$ & 774 Mio. \\
\hline $\begin{array}{c}\text { Function transfer (model } \\
\text { with ad-hoc variables) }\end{array}$ & $107(98 ; 116)$ & 429 Mio. & $111(102 ; 121)$ & 774 Mio. \\
\hline
\end{tabular}

Note: ${ }^{1}$ Mean estimates and confidence intervals have been calculated with the delta method.

Nevertheless, the results of both variants of function transfer lead to very similar value estimates since the population values of the variables gender, education and household size are very similar for Beijing and Shanghai. Irrespective of whether we use a theory-driven model with income as the only explanatory variable or the more fully specified model, we obtain a mean WTP of 111 RMB per month and household for Shanghai. This figure is slightly higher than the point estimate derived from the 
Beijing sample. This difference is a result of the difference in household income levels at both sites; since, in Shanghai, households dispose of approximately 2000 RMB per month more than an average Beijing household and because of the positive relationship between income and WTP, mean WTP in Shanghai is higher than in Beijing. Since the price level of consumer goods is approximately the same in both cities, we conclude that Shanghai residents show a higher appreciation of the water management project than Beijing residents.

Hence, depending on the variant of benefit transfer technique we apply, we obtain different WTP estimates. While the difference between mean WTP per household obtained from the two approaches is not statistically significant, the two social value estimates differ substantially due to the difference in population size. Unfortunately, we lack information in order to assess whether 107 RMB or 111 RMB comes closer to a Shanghai resident's "true" WTP for the Tarim water management project. Furthermore, we cannot even conclude that at least one of the two figures is valid. In order to assess the validity of the transferred values, we would have to assess Shanghai residents' WTP for improved environmental conditions in the Tarim Basin in a separate CVM study.

\subsection{Approximating the Megacity-Wide Social Value}

Finally, even though we lack sufficiently comprehensive data for this purpose, we want to present at least a rough approximation of the overall passive use values accruing from a more sustainable water management to people living in Chinese megacities far away from the Tarim Basin. Of course, including the WTP of megacity residents in a cost-benefit analysis of the Tarim water management project leads to a better approximation of the overall social benefit generated by such a project but it still underestimates the overall benefit since also people in smaller cities might appreciate that project. Including them also in a cost-benefit analysis using benefit transfer would be problematic at least when using the value transfer approach because we cannot expect the average WTP of people in smaller (and poorer) cities to be the same as in Beijing and Shanghai. In our demonstration example here, we confine ourselves to the largest Chinese megacities, namely Beijing, Shanghai, Guangzhou, Tianjin and Shenzhen.

As displayed in Table 6, the households in these five megacities have quite different levels of income at their disposal. Due to these differences in one of the key determinants of WTP, function transfer appears more appropriate than simple value transfer. Using the value function estimated based on the primary CVM study in Beijing ( $c f$., Model 1 in Table 4) WTP in Guangzhou amounts to 109 RMB per household; we obtain an average WTP estimate of 108 RMB for Tianjin and 112 RMB for Shenzhen ( $c f$., Table 6). Multiplying these numbers with the total number of households gives the city-specific social value estimates. We arrive at an overall social value of 2.4 billion RMB per month by summing up these estimates for all five megacities. Needless to say, this figure dramatically exceeds the figure we would have obtained when only accounting for the households directly affected by the water management project in question, i.e., households in the Tarim Basin.

It is to be noted, however, that this estimate is full of uncertainty due to the above mentioned methodological weaknesses of the benefit transfer approach as such and also because of several assumptions we had to make in order to calculate the megacity-wide social value in the present study. First of all, it turned out to be difficult to find income data for Guangzhou, Tianjin and Shenzhen. With exception of the city of Shenzhen, none of these cities publish their statistical yearbooks online. 
For this reason, we had to rely on other available sources that are less complete and not strictly comparable to the data published by the municipal bureaus of statistics. For example, we lack information regarding average household size for Guangzhou and Tianjin and found only information on disposable per capita income. Assuming that households in Guangzhou and Tianjin are approximately as small as households in Beijing and Shanghai, monthly disposable household income was approximated by multiplying monthly per capita income by three. According to the Statistical Yearbook, an average household in Shenzhen counts 3.67 members. Since this figure is substantially higher than the (assumed) household size in the remaining cities, average monthly disposable household income is also the highest in Table 6. It could be the case, however, that households in Guangzhou and Tianjin consist of more than the assumed three persons. If this holds true, we systematically underestimate the average household income and hence average WTP in these two cities.

Table 6. Approximation of the overall social value.

\begin{tabular}{|c|c|c|c|c|c|c|}
\hline $\begin{array}{l}\text { City Characteristics and } \\
\text { Welfare Measures }\end{array}$ & Beijing & Shanghai & Guangzhou $^{1}$ & Tianjin $^{2}$ & Shenzhen ${ }^{3}$ & Total \\
\hline $\begin{array}{l}\text { Monthly disposable household } \\
\text { income (in } 1000 \mathrm{RMB} \text { ) }\end{array}$ & 8.485 & 10.512 & 9.513 & 8.164 & 11.101 & -- \\
\hline $\begin{array}{l}\text { Monthly WTP per household } \\
\text { (in RMB) }\end{array}$ & 107 & 111 & 109 & 108 & 112 & -- \\
\hline Number of households & 4.006 Mio. & 6.969 Mio. & 4.280 Mio. & 3.841 Mio. & 2.872 Mio. & 21.968 \\
\hline Social value (in RMB) & 429 Mio. & 774 Mio. & 467 Mio. & 415 Mio. & 322 Mio. & 2407 Mio. \\
\hline
\end{tabular}

Notes: ${ }^{1}$ Values approximated based on [39]; ${ }^{2}$ Values approximated based on [40]; ${ }^{3}$ Values reported in [41].

The validity of our social value assessment is further threatened by some degree of uncertainty inherent to the number of households in the five cities of interest. While the Statistical Yearbooks for Beijing and Shanghai provide detailed information regarding the number of urban households, we lack this essential information for Guangzhou, Tianjin and Shenzhen. The figures reported in Table 6 are likely to overestimate the actual number of urban households because we only dispose of data about the permanent residents, including urban and rural households, in these cities. These considerations show how problematic the use of the benefit transfer method is in practice.

Summing up, the benefit transfer exercise reported in this section indicates that the passive use value of a more sustainable water management in the Tarim Basin seems to be very high as compared to its use value since this project seems to be appreciated also by people living far away from the project site. For the assessment of this appreciation in terms of WTP the benefit transfer technique offers a rather cost-saving possibility to enhance a cost-benefit analysis conducted on site only. Nevertheless the assumptions to be made in order to apply this approach in practice are rather heroic as has been shown in this section. Therefore, one should be very careful when interpreting the results of benefit transfer studies.

\section{Conclusions}

In this paper we deal with the problem of missing data in the context of environmental cost-benefit analysis. Since environmental projects of greater ecological importance (like our example of fighting desertification in Northwest China) typically create benefits not only for the people living on the 
project site but potentially for all people living in a country a benefit assessment study carried out at the project site only would lead to a systematic underestimation of the total social benefits accruing from such a project. Since it is not possible from a financial as well as an organizational perspective to conduct benefit assessment studies like CVM surveys all over China, we suggest "approximating" the total social value of environmental projects by using the benefit transfer technique. We suggest carrying out one CVM survey at the project site where use values, which accrue to people actively utilizing the environment, as well as passive use values, which are not connected to any (observable) utilization activities, accrue to the people there. Then different classes of other possible study sites (e.g., rural areas and villages, small cities, middle-sized cities, megacities), which are far away from the project site, should be defined and, for each category, one representative study site (e.g., one megacity) should be selected. In these remote study sites, people will typically obtain only passive use benefits from the environmental improvement realized at the project site. At each of the selected representative study sites, a CVM survey can be conducted and its results can be extrapolated to the whole class of sites it represents by making use of the benefit transfer technique. Of course, the overall cost of these assessment studies will increase as the number of representative study sites and with it the number of CVM surveys to be conducted increases. In our empirical example here, we confined our analysis to the class of five Chinese megacities. As a representative study site we chose Beijing and then we showed how the WTP results from a CVM survey conducted there can be extrapolated to the other megacities. Such a confinement benefit transfer allows the enhancement of the quality and comprehensiveness of benefit assessment in the environmental sector without boosting the valuation costs.

Our empirical study clearly demonstrates the shortcomings of the benefit transfer methodology and has, of course, its own limitations. First, the primary study underlying the benefit transfer exercise has several weak points, including the limited sample size, covering only $0.06 \%$ of all households in Beijing, the non-random sampling approach and the well-known drawbacks of personal interviews (social desirability bias, interviewer effects, etc.). Second, we had to adopt one of the central and at the same most criticized assumptions underlying the benefit transfer approach, namely the assumption on equal preferences in the primary population and the target population. It may be the case, however, that in other Chinese megacities WTP is driven by other factors than those identified in Beijing or that a substantially larger share of people is completely indifferent about the environmental impacts of a more sustainable water management in the Tarim Basin. Third, in the exemplary benefit transfer exercise presented in Section 4.2, we only calculated monthly values. For the conduct of a cost-benefit analysis these values would have to be extrapolated over the project duration, which would involve additional assumptions regarding the appropriate discount rate, expected inflation, etc., implying even more uncertainty about the overall social benefit of the water management project. Fourth, we lack information to verify whether our benefit transfer exercise was "successful". Further research on the benefits of a more sustainable water management in the Tarim Basin accruing to the inhabitants of other Chinese megacities would be needed in order to test the validity of the WTP estimates provided in Section 4.2. Finally, we did not carry out a complete cost-benefit analysis but concentrated on the benefit assessment. Unlike the social benefits, the social costs of water management projects can be calculated relatively easily based on market prices, labor and material costs. However, such data is sometimes difficult to access, especially in countries like China with strict data protection rules. 


\section{Acknowledgments}

This research is part of the Sino-German joint research project SuMaRiO. SuMaRiO is funded by the German Ministry of Education and Research (Award number 01 LL0918F) and also supported by the National Basic Research Program of China (973 Program, 2012CB955903). We would like to express our thanks to Dai Tang-Ping, professor of sociology at Minzu University of China, whose students conducted the CVM interviews in Beijing.

\section{Author Contributions}

Michael Ahlheim and Oliver Frör jointly led the SuMaRiO subproject "Contingent Valuation of a more sustainable oasis management in the Tarim Basin". Sonna Pelz was responsible for the data collection and data analysis. Jiang Tong and Luo Jing provided important advice on the questionnaire design, sampling frame and sampling mode. Both supported and facilitated the fieldwork in China. All authors contributed to the preparation of the manuscript.

\section{Appendix}

\section{A.1. Project and Payment Scenario}

Project Scenario:

"Scientists have developed a program with the overarching goal to improve the living conditions in the area along the Tarim River for man and nature. This program is called the Tarim Environmental Preservation Plan and implies a science-based water management that ensures that more and more water arrives in the lower reaches of the Tarim River, so that the riparian forests and grasslands can recover there. Once the river and its natural environment has fully recovered, the area will be less exposed to sandstorms and dust; typical animals and plants will survive; also, the living conditions of future generations will improve."

Payment Scenario plus Referendum Question:

"In order to get the Tarim Environmental Preservation Plan financed, Central Government needs to transfer more money to the Tarim area. In order to finance these transfer payments, government would have to increase taxes if TEPP was realized. This would lead to rising monthly expenditures for households. Economists estimate that the proposed program would increase an average Beijing household's monthly expenditures by approximately (10/25/50/75/100/200) RMB. We would like to find out whether Beijing citizens support the implementation of the Tarim Environmental Preservation Plan although it implies an increase in their monthly expenditures. Considering that your monthly household expenditures would increase by approximately [BID] RMB through the program, would you personally be willing to support it?" 


\section{A.2. Variable Description}

Table A1. Description of variables used in the regression models.

\begin{tabular}{|c|c|c|c|c|c|}
\hline Variable & Description & Mean & Std. Dev. & Min. & Max. \\
\hline WTP & $\begin{array}{l}\text { "Considering that your monthly household expenditures } \\
\text { would increase by approximately (BID) RMB through the } \\
\text { program would you personally be willing to support it?" } \\
\qquad(1=\mathrm{yes}, 0=\mathrm{no})\end{array}$ & 0.540 & 0.498 & 0 & 1 \\
\hline BID & Bid amount & 89.440 & 68.270 & 10 & 200 \\
\hline INCOME & Monthly disposable household income in $1000 \mathrm{RMB}$ & 8.498 & 7.755 & 0.5 & 50 \\
\hline MALE & Gender of the respondent $(1=$ male, $0=$ female $)$ & 0.506 & 0.500 & 0 & 1 \\
\hline AGE & Age of the respondent & 40.227 & 15.420 & 18 & 84 \\
\hline EDUCATION & $\begin{array}{l}\text { Level of education of the respondent }(1=\text { did not graduate } \\
\text { from primary school, } 7=\text { master degree or higher })\end{array}$ & 4.320 & 1.342 & 1 & 7 \\
\hline HH_SIZE & Number of people living in the respondent's household & 2.871 & 1.400 & 1 & 9 \\
\hline
\end{tabular}

\section{Conflicts of Interest}

The authors declare no conflict of interest.

\section{References}

1. Executive Order 12291. Federal Register; National Archives: College Park, MD, USA, 1981; Volume 46.

2. Executive Order 12866. Federal Register; National Archives: College Park, MD, USA, 1993; Volume 58.

3. Loomis, J.; Kent, P.; Strange, L.; Fausch, K.; Covich, A. Measuring the total economic value of restoring ecosystem services in an impaired river basin: Results from a contingent valuation survey. Ecol. Econ. 2000, 33, 103-117.

4. Freeman, A.M.; Herriges, J.A.; Kling, C.L. The Measurement of Environmental and Resource Values: Theory and Methods; Resources for the Future: New York, NY, USA, 2014.

5. Hanley, N.; Mourato, S.; Wright, R.E. Choice modelling approaches: A superior alternative for environmental valuation? J. Econ. Surv. 2001, 15, 435-462.

6. Adamowicz, W.; Boxall, P.; Williams, W.; Louviere, J. Stated preference approaches for measuring passive use values: Choice experiments and contingent valuation. Am. J. Agric. Econ. 1998, 80, 64-75.

7. Mills, L.S.; Soule, M.E.; Doak, D.F. The Keystone-Species Concept in Ecology and Conservation. BioScience 1993, 43, 219-224.

8. Ahlheim, M. Handbook of Utility Theory; Barberà, S., Ed.; Kluwer: Dordrecht, The Netherlands, 1998; pp. 447-568.

9. Ahlheim, M.; Frör, O. Valuing the non-market production of agriculture. Agrarwirtschaft 2003, 52, 356-369. 
10. Carson, R.T.; Hanemann, W.M. Handbook of Environmental Economics, Volume 2: Valuing Environmental Changes; Maler, K.-G., Vincent, J.R., Eds.; Elsevier, North-Holland: Amsterdam, The Netherlands, 2005; pp. 821-936.

11. Bateman, I.; Carson, R.T.; Day, B.; Hanemann, M.; Hanley, N.; Hett, T.; Jones-Lee, M.; Loomes, G.; Mourato, S.; Özdemiroglu, E.; et al. Economic Valuation with Stated Preference Techniques: A Manual; Elgar: Cheltenham, UK, 2002.

12. Arrow, K.; Solow, R. Report of the NOAA Panel on Contingent Valuation; Resources of the Future: Washington, DC, USA, 1993.

13. Nunes, P.A.L.D. The Contingent Valuation of Natural Parks: Assessing the Warmglow Propensity Factor; Elgar: Cheltenham, UK, 2002.

14. Bateman, I.J.; Brouwer, R.; Ferrini, S.; Schaafsma, M.; Barton, D.N.; Dubgaard, A.; Hasler, B.; Hime, S.; Liekens, I.; Navrud, S. Making benefit transfers work: Deriving and testing principles for value transfers for similar and dissimilar sites using a case study of the non-market benefits of water quality improvements across Europe. Environ. Resour. Econ. 2011, 50, 365-387.

15. Richardson, L.; Loomis, J.; Kroeger, T.; Casey, F. The role of benefit transfer in ecosystem service valuation. Ecol. Econ. 2015, 115, 51-58.

16. Wilson, M.A.; Hoehn, J.P. Valuing environmental goods and services using benefit transfer: The state-of-the art and science. Ecol. Econ. 2006, 60, 335-342.

17. Pearce, D.; Atkinson, G.; Mourato, S. Cost-benefit Analysis and the Environment: Recent Developments; OECD: Paris, France, 2006.

18. Loomis, J.; Richardson, L.; Kroeger, T.; Casey, F. Valuing ecosystem services using benefit transfer: Separating credible and incredible approaches. In Valuing Ecosystem Services. Methodological Issues and Case Studies; Ninan, K.N., Ed.; Edward Elgar Publishing Limited: Cheltenham, UK, 2014; pp. 78-89.

19. Johnston, R.J.; Rosenberger, R.S. Methods, Trends and Controversies in Contemporary Benefit Transfer. J. Econ. Surv. 2010, 24, 479-510.

20. Boyle, K.J.; Bergstrom, J.C. Benefit transfer studies: Myths, pragmatism, and idealism. Water Resour. Res. 1992, 28, 657-663.

21. Ahlheim, M.; Lehr, U. Nutzentransfer: Das Sparmodell der Umweltbewertung. Perspekt. Wirtsch. 2003, 3, 85-104.

22. Thevs, N. Water Scarcity and Allocation in the Tarim Basin: Decision Structures and Adaptations on the Local Level. J. Curr. Chin. Aff. 2011, 3, 113-137.

23. Zhang, J.; Wu, G.; Wang, Q.; Li, X. Restoring environmental flows and improving riparian ecosystem of Tarim River. J. Arid Land 2010, 2, 43-50.

24. Chen, Y.; Xu, C.; Chen, Y.; Liu, Y.; Li, W. Progress, Challenges and Prospects of Eco-Hydrological Studies in the Tarim River Basin of Xinjiang, China. Environ. Manag. 2013, $51,138-153$.

25. Lu, Z.; Zhao, L.; Dai, J. A study of water resource management in the Tarim Basin, Xinjiang. Int. J. Environ. Stud. 2010, 67, 245-255.

26. Huang, X.; Chen, Y.; Ma, J.; Chen, Y. Study on change in value of ecosystem service function of Tarim River. Acta Ecol. Sin. 2010, 30, 67-75. 
27. Niu, X.; Wang, B.; Liu, S.; Liu, C.; Wei, W.; Kauppi, P.E. Economical assessment of forest ecosystem services in China: Characteristics and implications. Ecol. Complex. 2012, 11, 1-11.

28. Xu, C.Z.; Li, Q.; Wang, W.X. Contingent Valuation Method Assessment of the Ecological Benefits of Populus Euphratica Forest Based on Consumer Perspective-Taking the Typical Area in Tarim River Basin as an Example. Adv. Mater. Res. 2014, 962-965, 703-709.

29. Krutilla, J. Conservation reconsidered. Am. Econ. Rev. 1967, 56, 777-786.

30. Ahlheim, M.; Frör, O.; Luo, J.; Pelz, S.; Jiang, T.; Yiliminuer. The Social Value of Environmental Improvements in the Tarim Basin-toward a comprehensive assessment in a heterogeneous setting. Environ. Nat. Resour. Res. 2015, 5, doi:10.5539/enrr.v5n2p49.

31. Rumbaur, C.; Thevs, N.; Disse, M.; Ahlheim, M.; Brieden, A.; Cyffka, B.; Duethmann, D.; Feike, T.; Frör, O.; Gärtner, P.; et al. Sustainable management of river oases along the Tarim River (SuMaRiO) in Northwest China under conditions of climate change. Earth Syst. Dynam. 2015, 6, 83-107.

32. Bishop, R.C.; Heberlein, T.A. Measuring Values of Extra-Market Goods: Are Indirect Measures Biased? Am. J. Agric. Econ. 1979, 61, 916-930.

33. Hanemann, W.M. Welfare evaluations in contingent valuation experiments with discrete response data: Reply. Am. J. Agric. Econ. 1989, 71, 1057-1061.

34. Beijing Municipal Bureau of Statistics. 2012 Beijing Statistical Yearbook; China Statistics Press: Beijing, China, 2013.

35. Ahlheim, M.; Börger, T.; Frör, O. Replacing rubber plantations by rain forest in Southwest China-Who would gain and how much? Environ. Monit. Assess. 2015, 187, 1-20.

36. Ahlheim, M.; Schneider, F. Considering household size in contingent valuation studies. Environ. Econ. 2013, 4, 112-123.

37. Ahlheim, M.; Frör, O.; Langenberger, G.; Pelz, S. Chinese urbanities and the preservation of rare species in remote parts of the country: The example of eaglewood. Environ. Econ. 2014, 5, 32-43.

38. Shanghai Municipal Statistics Bureau. 2012 Shanghai Statistical Yearbook; China Statistics Press: Shanghai, China, 2013.

39. Gzstats 2013; Guangzhou Statistical Manual: Guangzhou, China, 2013.

40. 2013 Tianjin Economic and Social Development Statistics Bulletin (Economic and Social Statistic for Tianjin, 2013). Available online: http://www.ce.cn/ (accessed on 14 May 2015).

41. Shenzhen Municipal Bureau of Statistics. 2012 Shenzhen Statistical Yearbook; China Statistics Press: Shenzhen, China, 2013.

(C) 2015 by the authors; licensee MDPI, Basel, Switzerland. This article is an open access article distributed under the terms and conditions of the Creative Commons Attribution license (http://creativecommons.org/licenses/by/4.0/). 